\title{
SPATIOTEMPORAL VARIATION IN SURVIVAL RATES: IMPLICATIONS FOR POPULATION DYNAMICS OF YELLOW-BELLIED MARMOTS
}

\author{
Arpat Ozgul,${ }^{1,4}$ Kenneth B. Armitage, ${ }^{2}$ Daniel T. Blumstein, ${ }^{3}$ and Madan K. Oli ${ }^{1}$ \\ ${ }^{1}$ Department of Wildlife Ecology and Conservation, University of Florida, Gainesville, Florida 32611-0430 USA \\ ${ }^{2}$ Department of Ecology and Evolutionary Biology, University of Kansas, Lawrence, Kansas 66045 USA \\ ${ }^{3}$ Department of Ecology and Evolutionary Biology, 621 Young Drive South, University of California, \\ Los Angeles, California 90095-1606 USA
}

\begin{abstract}
Spatiotemporal variation in age-specific survival rates can profoundly influence population dynamics, but few studies of vertebrates have thoroughly investigated both spatial and temporal variability in age-specific survival rates. We used 28 years (1976-2003) of capture-mark-recapture (CMR) data from 17 locations to parameterize an age-structured Cormack-Jolly-Seber model, and investigated spatial and temporal variation in age-specific annual survival rates of yellow-bellied marmots (Marmota flaviventris). Survival rates varied both spatially and temporally, with survival of younger animals exhibiting the highest degree of variation. Juvenile survival rates varied from $0.52 \pm 0.05$ to $0.78 \pm 0.10$ among sites and from $0.15 \pm 0.14$ to $0.89 \pm 0.06$ over time. Adult survival rates varied from $0.62 \pm 0.09$ to $0.80 \pm 0.03$ among sites, but did not vary significantly over time. We used reverse-time CMR models to estimate the realized population growth rate $(\lambda)$, and to investigate the influence of the observed variation in age-specific survival rates on $\lambda$. The realized growth rate of the population closely covaried with, and was significantly influenced by, spatiotemporal variation in juvenile survival rate. High variability in juvenile survival rates over space and time clearly influenced the dynamics of our study population and is also likely to be an important determinant of the spatiotemporal variation in the population dynamics of other mammals with similar life history characteristics.
\end{abstract}

Key words: age-specific survival; capture-mark-recapture (CMR); Cormack-Jolly-Seber model; environmental covariates; Marmota flaviventris; population dynamics; Pradel's reverse-time model; spatial variation; spatiotemporal population dynamics; temporal variation; yellow-bellied marmot.

\section{INTRODUCTION}

Populations inhabiting spatially heterogeneous landscapes are influenced by multiple environmental factors that vary over space and time (Orzack and Tuljapurkar 1989, Tuljapurkar 1990, Post et al. 1997). Such spatiotemporal variation in environmental factors can cause differences in vital demographic rates, and these differences can significantly influence the dynamics, regulation, and persistence of populations (Kareiva 1990, Pulliam and Danielson 1991, Tilman and Kareiva 1997).

Survival is a crucial demographic parameter influencing population growth rate, and thus the population dynamics, of many populations (Stearns 1992, Pfister 1998, Heppell et al. 2000, Sæther and Bakke 2000, Oli and Dobson 2003), and it can be influenced by spatiotemporal variation in factors such as weather, habitat quality, disease, competition, and predation (e.g., Jorgenson et al. 1997, Coulson et al. 1999, 2000, Farand et al. 2002). Although several studies have examined the causes and population dynamic conse-

Manuscript received 1 June 2005; revised 2 September 2005; accepted 21 September 2005. Corresponding Editor: A. M. Bronikowski.

${ }^{4}$ E-mail: arpat@ufl.edu quences of temporal variation in survival (e.g., Francis 1995, Sæther 1997, Coulson et al. 2000, Blums et al. 2002, Oli and Armitage 2004), less attention has been paid to the influence of spatial heterogeneity on this important demographic parameter. Nonetheless, a significant spatial variation has been reported for a number of species. For example, Coulson et al. (1999) observed spatial differences in survival rates among local populations of Soay sheep (Ovis aries). Waser et al. (1995) attributed spatial differences in survival of dwarf mongooses (Helogale parvula) to variation in habitat quality. Several studies on ground squirrels have reported elevational variation in the demographic parameters (Bronson 1979, Zammuto and Millar 1985, Dobson and Oli 2001, Gillis et al. 2005). However, the population dynamic consequences of such variation have rarely been addressed.

Survival rates of many long-lived species vary by age; individuals of different ages often respond differentially to changes in environmental factors. In general, survival rates of young animals are lower than those of adults, and also are expected to be more variable over space and time (e.g., Fowler and Smith 1981, Douglas and Leslie 1986, Clutton-Brock et al. 1987, Gaillard et al. 1998, Portier et al. 1998, Doherty et al. 2004). Older individuals are typically less severely affected by 


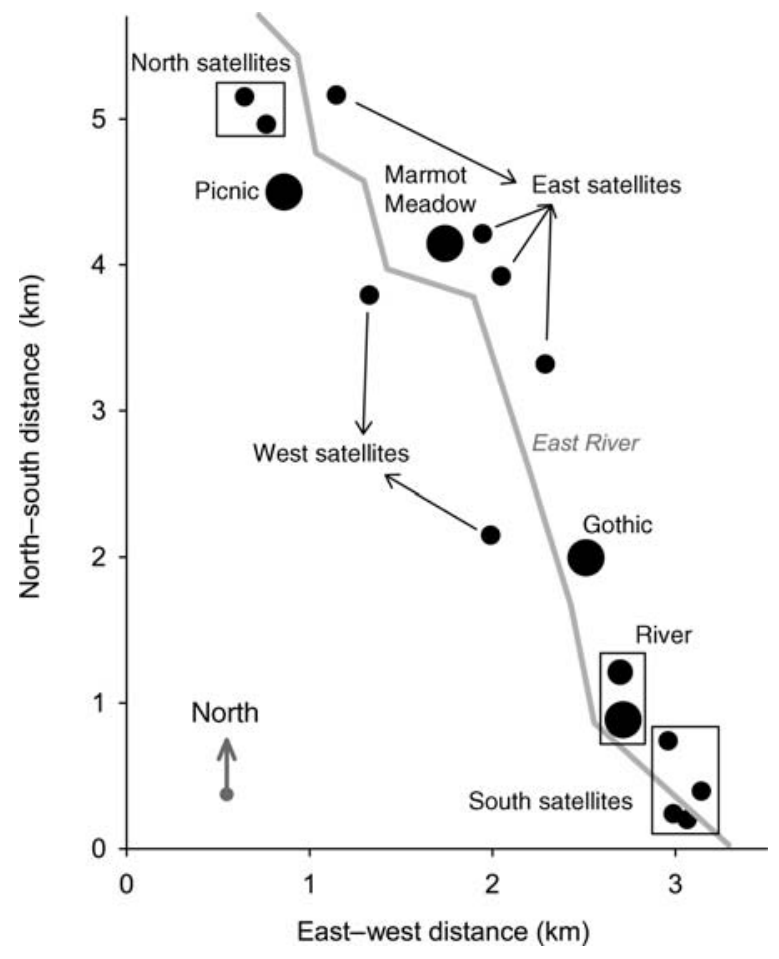

FIG. 1. The spatial structure of the yellow-bellied marmot metapopulation in Colorado, USA. Seventeen sites are grouped into four colonies (River, Gothic, Marmot Meadow, and Picnic) and four satellite groups (south, west, east, and north satellites).

spatiotemporal changes, and their survival rates are expected to be less variable. Elucidating the interactive effects of extrinsic and intrinsic factors (e.g., age, stage) on survival rates is important for a thorough understanding of the dynamics, regulation, and persistence of populations. However, simultaneous examinations of both spatial and temporal variation in extrinsic factors, and their influence on age-specific survival rates, have been rare (but see Ringsby et al. 1999, Sæther et al. 1999, Graham and Lambin 2002). This is due primarily to the difficulty in collecting demographic data over large spatial and temporal scales. Consequently, spatiotemporal variations in age-specific survival rates of longlived species remain poorly understood.

We used data from a long-term study of the yellowbellied marmot (Marmota flaviventris; see Plate 1) to investigate the spatiotemporal variation in age-specific survival rates. Using an age-structured Cormack-JollySeber (CJS) model, we analyzed 28 years of capturemark-recapture (CMR) data from 17 discrete habitat patches within our study site. We estimated age-specific survival rates, and examined both spatial and temporal variation in these rates. We also tested a series of hypotheses concerning the effects of key environmental factors on the observed variation in survival rates. Finally, using a Pradel's reverse-time CMR model, we estimated the realized population growth rate, and investigated the influence of the observed variation in age-specific survival rates on the realized population growth rate, and hence on the dynamics of the yellowbellied marmot population.

\section{Materials and Methods \\ Study area and species}

The yellow-bellied marmot is a large, diurnal, burrowdwelling rodent, occupying montane regions of western North America (Frase and Hoffmann 1980, Armitage 2003). Our study area is located in the Upper East River Valley near the Rocky Mountain Biological Laboratory, Gothic, Colorado $\left(38^{\circ} 57^{\prime} \mathrm{N}, 106^{\circ} 59^{\prime} \mathrm{W}\right.$; see Plate 1). The marmots in our study area occupy 17 discrete habitat patches (Fig. 1). The elevation of marmot sites varies from 2700 to $3100 \mathrm{~m}$ above sea level. Habitat characteristics vary within and between sites from rolling grassy meadows to steeper talus slopes (Svendsen 1974). These distinct habitat patches vary in size and quality, ranging from satellite sites as small as $0.01 \mathrm{ha}$, to colony sites as large as 7.2 ha. Colony sites are occupied by one or more matrilines, each typically consisting of one or more adult females, yearlings, and juveniles with an adult male defending one or more matrilines, whereas, satellite sites are typically occupied by a single adult female, her litter, and sometimes an adult male (Armitage 1991, 1998). The biology of yellow-bellied marmots in Colorado is described in detail by Armitage (1991, 2003).

\section{Field methods}

From 1962 to 2003, yellow-bellied marmots were livetrapped and individually marked using numbered ear tags (details in Armitage 1991). Animal identification number, sex, mass, and reproductive condition were recorded for each animal. Trapping concurrently occurred in 17 sites known to be occupied by marmots.

Four variables were used as site-specific covariates in the CMR analyses: (1) elevation (m), (2) aspect (slope direction, 1, southwest; 0 , northeast), (3) slope (degrees), and (4) the average number of adult females per site. The Upper East River Valley stretches in a southeastnorthwest direction, gaining elevation toward the northwest. Marmot sites on the west side of the East River Valley have steeper slopes facing northeast $\left(38^{-}-98^{\circ}\right)$, whereas sites on the east side are located on gradually inclined meadows generally facing southwest $\left(183-280^{\circ}\right)$.

Seven time-specific climatic variables were used as temporal covariates in the CMR analyses: (1) length of the growing season (number of days between first bare ground and the first killing frost), (2) annual precipitation (centimeters), and (3) monthly mean summer (May-August) temperature $\left({ }^{\circ} \mathrm{C}\right)$ were obtained from Crested Butte Weather Station (National Oceanic and Atmospheric Administration), $\sim 10 \mathrm{~km}$ south of the study area, whereas (4) duration of permanent snow cover (days), (5) annual amount of snow fall (centimeters), (6) Julian date (1 January) of first permanent 
snow pack, and (7) Julian date (1 January) of first bare ground were obtained from Rocky Mountain Biological Laboratory, Gothic, Colorado. Mean monthly temperature during the active season (May-August) ranged from $9.7^{\circ}$ to $11.9^{\circ} \mathrm{C}$, and annual precipitation ranged from 38.6 to $86.6 \mathrm{~cm}$. For a detailed description of timespecific climatic factors, see Schwartz and Armitage (2005).

\section{Capture-Mark-Recapture (CMR) analysis}

Although our study spanned 42 years (1962-2003), we analyzed data from the last 28 years (1976-2003), because this period provided the most comprehensive CMR data for the entire region. We used data from 860 resident females; all of these females were captured and marked as pups and their ages were known exactly. Sixty-nine known dispersers that moved among sites (identified based on trapping data) were excluded from the analyses. Seventeen sites were grouped into eight categories on the basis of site quality and location (Fig. 1). Four major colony sites were considered separately: (1) Picnic, (2) River (two adjacent sites were grouped into one), (3) Marmot Meadow, and (4) Gothic. Satellite sites were typically occupied by few individuals. We assumed that survival rates of marmots occupying adjacent satellite sites that share similar habitat characteristics (e.g., size, aspect, elevation) were similar. Therefore, satellite sites were grouped with respect to their location: (5) north satellites, (6) west satellites, (7) east satellites, and (8) south satellites.

We implemented the CMR models using Program MARK (White and Burnham 1999). We used an agestructured CJS model (Lebreton et al. 1992, 1993) to estimate and model age-specific apparent survival $(\phi)$ and recapture rates $(\rho)$, and to investigate the spatial and temporal variation in these rates. We used Program UCARE V2.02 (Choquet et al. 2003) to test the goodness-of-fit of the CJS model. We used Akaike's Information Criterion, corrected for small sample size, $\left(\mathrm{AIC}_{\mathrm{c}}\right)$ for model comparison, and for the identification of the most parsimonious model from a candidate model set (Burnham and Anderson 2002). Model comparison was based on the differences in $\mathrm{AIC}_{\mathrm{c}}$ values, $\Delta \mathrm{AIC}_{\mathrm{c}}$. We used $\mathrm{AIC}_{\mathrm{c}}$ weight as a measure of relative support for each model. The underlying process standard deviation $(\sigma)$ of the estimated parameters over space (or time) was used as an estimate of the spatial (or temporal) variation. The $\sigma$ was estimated using the variance components procedure implemented in Program MARK, which is an extension of the procedure described in Burnham et al. (1987).

The CMR analyses proceeded in a stepwise fashion. In preliminary analyses, we tested for site and time effects on overall survival rates. We then proceeded to determine the appropriate age structure for our study population. Previous demographic studies of yellowbellied marmots have used two or more age classes (Schwartz et al. 1998, Oli and Armitage 2004). Thus, we
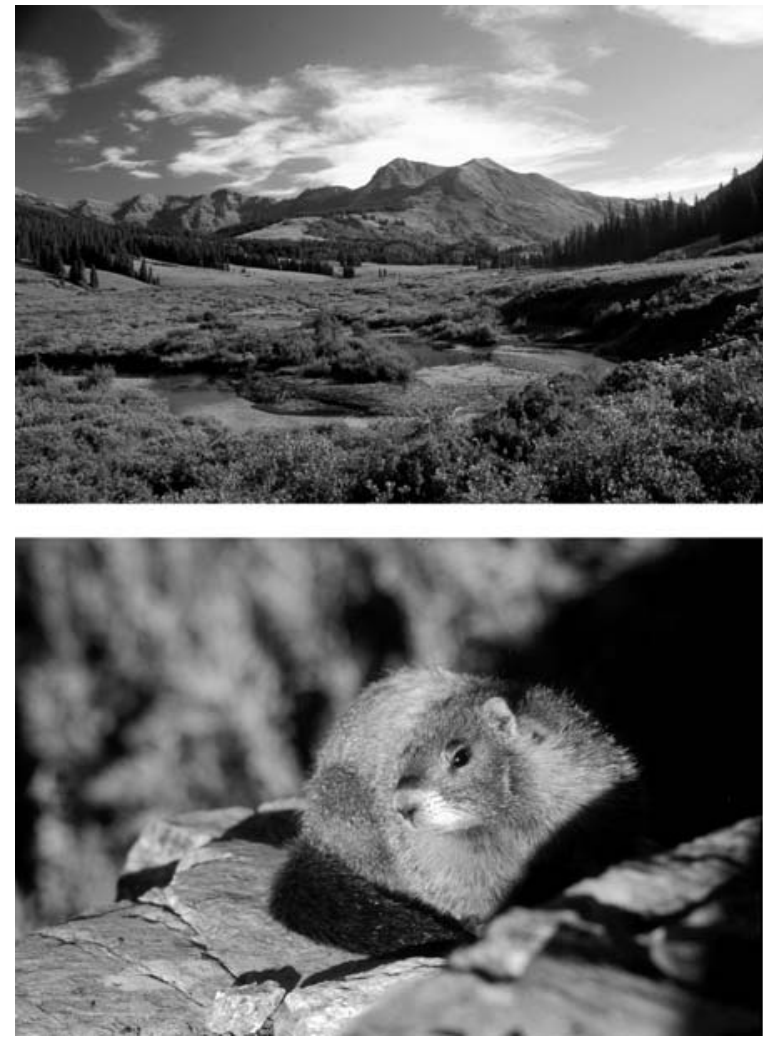

Plate 1. (Top) The Upper East River Valley near the Rocky Mountain Biological Laboratory, Gothic, Colorado, USA. (Bottom) The yellow-bellied marmot, Marmota flaviventris. Photo credit: A. Ozgul.

parameterized and compared the following models with alternative age structures: no age structure, two age classes (juveniles, $0-1 \mathrm{yr}$; adults, $>1 \mathrm{yr}$ ), three age classes (juveniles, 0-1 yr; yearlings, 1-2 yr; and adults, $>2 \mathrm{yr}$ ), and four age classes (juveniles, $0-1 \mathrm{yr}$; yearlings, $1-2 \mathrm{yr}$, subadults, 2-3 yr; and adults, $>3 \mathrm{yr}$ ). Although our data did not permit analysis of models with more than four age classes, we believe that the range of age structure considered here is adequate because, in many species of mammals, survival rates of older animals are generally less variable than those of younger animals (Gaillard et al. 1998, Schwartz et al. 1998). We also investigated the spatial variation in age-specific survival rates by testing for the site effect. Next, using the most parsimonious model, we investigated the temporal variation in agespecific and site-specific survival rates. We considered main effects as well as additive and interactive effects of site and time on age-specific survival rates (Williams et al. 2001). We note that the order in which site and time effects were included in the model did not influence the results of model selection; testing for the time effect first, and then testing for the site effect resulted in the same final models. To investigate the effect of site quality on spatiotemporal variation in age-specific survival rates, we further grouped eight sites into two major quality 
TABLE 1. Analysis of the age structure and spatial variation in age-specific apparent survival rates for the yellow-bellied marmot, using Cormack-Jolly-Seber models.

\begin{tabular}{|c|c|c|c|c|c|}
\hline No. & Model & $\mathrm{AIC}_{\mathrm{c}}$ & $\Delta \mathrm{AIC}_{\mathrm{c}}$ & $\mathrm{w}_{i}$ & np \\
\hline 1 & $\phi_{\text {juv }}(s) \phi_{\text {ad }}(s) \rho\left(s^{\prime}\right) \dagger$ & 2666.17 & 45.89 & 0.000 & 22 \\
\hline 2 & $\phi_{\text {juv }}(s) \phi_{\text {yrl }}(s) \phi_{\text {ad }}(s) \rho\left(s^{\prime}\right) \ddagger$ & 2622.63 & 2.35 & 0.170 & 30 \\
\hline 3 & $\phi_{\text {juv }}(s) \phi_{\text {yrl }}(s) \phi_{\text {subad }}(s) \phi_{\text {ad }}(s) \rho\left(s^{\prime}\right) \S$ & 2633.13 & 12.85 & 0.001 & 38 \\
\hline 4 & $\phi_{\text {juv }}(\cdot) \phi_{\text {yrl }}(s) \phi_{\text {ad }}(s) \rho\left(s^{\prime}\right) \ddagger$ & 2625.48 & 5.20 & 0.041 & 23 \\
\hline 5 & $\phi_{\text {juv }}(s) \phi_{\mathrm{yrl}}(\cdot) \phi_{\mathrm{ad}}(s) \rho\left(s^{\prime}\right)$ & 2626.28 & 6.00 & 0.027 & 23 \\
\hline 6 & $\phi_{\text {juv }}(s) \phi_{\text {yrl }}(s) \phi_{\text {ad }}(\cdot) \rho\left(s^{\prime}\right) \ddagger$ & 2620.28 & 0.00 & 0.549 & 23 \\
\hline 7 & $\dot{\phi}_{\text {juv }}(s) \dot{\phi}_{\mathrm{yrl}}(s) \dot{\phi}_{\mathrm{ad}}(\cdot) \rho(s) \dagger$ & 2622.71 & 2.43 & 0.163 & 25 \\
\hline 8 & $\phi_{\text {juv }}(s) \phi_{\mathrm{yrl}}(s) \phi_{\mathrm{ad}}(s) \rho(s) \ddagger$ & 2625.09 & 4.80 & 0.050 & 32 \\
\hline 9 & $\phi_{\text {juv }}(s) \phi_{\text {yrl }}(s) \phi_{\text {subad }}(\cdot) \phi_{\text {ad }}(\cdot) \rho\left(s^{\prime}\right) \S$ & 2622.32 & 2.03 & 0.152 & 24 \\
\hline 10 & $\phi_{\text {juv }}(s) \phi_{\text {ad }}(\cdot) \rho\left(s^{\prime}\right) \dagger$ & 2674.83 & 54.55 & 0.000 & 15 \\
\hline 11 & $\phi_{\text {juv }}(s) \phi_{\text {yrl }}(\cdot) \phi_{\text {ad }}(\cdot) \rho\left(s^{\prime}\right) \ddagger$ & 2623.54 & 3.26 & 0.082 & 16 \\
\hline
\end{tabular}

Notes: Akaike's Information Criterion corrected for small sample size $\left(\mathrm{AIC}_{\mathrm{c}}\right)$, differences in $\mathrm{AIC}_{\mathrm{c}}$ values $\left(\Delta \mathrm{AIC} \mathrm{C}_{\mathrm{c}}\right), \mathrm{AIC}_{\mathrm{c}}$ weights $\left(\mathrm{w}_{i}\right)$, and number of parameters $(\mathrm{np})$ are given for each model. Age classes used for this analysis are juvenile (juv, $\left.0-1 \mathrm{yr}\right)$, yearling (yr, 1-2 yr), subadult (subad, 2-3 yr), and adults ( $\mathrm{ad},>1 \mathrm{yr}$ for two-age-class model, $>2 \mathrm{yr}$ for three-age-class model, and $>3 \mathrm{yr}$ for four-age-class model). Symbols are: $\phi$, apparent annual survival rate; $\rho$, annual recapture rate; $s$, site effect; and $s^{\prime}$, modified site effect. A dot (.) indicates constant value of the parameter. The most parsimonious models are highlighted in bold.

$\uparrow$ Two-age-class model.

\$ Three-age-class model.

$\S$ Four-age-class model.

types (colony and satellite sites), and tested for time and site effects.

Using the most parsimonious model, we examined the potential influence of environmental covariates on observed spatial and temporal variation in age-specific survival rates. We tested for the effects of each covariate by modeling the logits of age-specific survival rates as a linear function of a site-specific or temporal covariate. Each temporal covariate was scaled to range between 0 and 1 . If the $95 \%$ confidence interval for the slope parameter $(\beta)$ did not include 0 , the relationship was considered statistically significant (Williams et al. 2001). Because we only had data on a subset of the environmental factors that could have influenced survival rates, we did not attempt to develop a predictive model with multiple environmental covariates. Instead, our goal was to identify the environmental factors that potentially influenced age-specific survival rates, so we considered the influence of each environmental covariate separately.

We used a Pradel's reverse-time CMR model (Pradel 1996) to estimate and model the realized population growth rate, and to investigate time and site specific population growth rates $(\lambda)$. RELEASE tests $2+3$ (implemented in Program MARK) were used for assessing goodness-of-fit of the Pradel's model. Spatial and temporal variation in $\lambda$ was examined as described for the CJS models. Because Pradel's models do not allow for age effect (Franklin 2001), estimates of $\lambda$ could be biased due to unaccounted differences in age-specific survival rates. Therefore, we also estimated and modeled the realized growth rate of the adult ( $>2 \mathrm{yr}$ ) segment of the population, and investigated the relative influence of the spatial and temporal variation in age-specific survival rates on adult population growth rate $\left(\lambda_{\mathrm{ad}}\right)$.

To assess the relative importance of age-specific survival rates to $\lambda_{\mathrm{ad}}$, we modeled $\lambda_{\mathrm{ad}}$ directly as a function of these rates (Nichols and Hines 2002, Nichols et al. 2003). Specifically, we asked: which age-specific survival rate most closely covaried (over space and time) with $\lambda_{\text {ad}}$ ? We used site-specific estimates of age-specific survival rates as a covariate for site effect on $\lambda_{\mathrm{ad}}$, and time-specific estimates as a covariate for time effect on $\lambda_{\mathrm{ad}}$. We used the slope parameter $(\beta)$ to relate the variation in the vital rate to variation in $\lambda_{\text {ad }}$ (Nichols et al. 2003).

\section{RESUlts}

\section{Spatiotemporal variation in overall survival rates}

Our general CJS model, $\phi(t \times s) \rho(t \times s)$, fit the data with a slight under-dispersion $\left(\chi_{150}^{2}=120.2, P=0.965\right)$. There was strong support for significant variation in the overall (i.e., age structure ignored) annual survival rates both among sites and through time (Appendix A). However, site and time effects were additive, and there was no evidence for interactive effects. The most parsimonious model included site effect, but no time effect, on recapture rates. Three colony sites (River, Picnic, and Marmot Meadow) were the largest and the most intensively studied sites. Constraining the recapture rates for these three sites to have the same value resulted in a more parsimonious model (Appendix A, model 16). The recapture rate was 0.98 for these three colony sites and 0.79 for the fourth colony site (Gothic). Recapture rates for the north, west, east, and south satellites were $0.91,0.85,0.69$, and 0.94 , respectively.

\section{Age structure and spatiotemporal variation in age-specific survival rates}

Among the candidate models with different age structures, the three-age-class model was the most parsimonious (Table 1, model 2). Among the threeage-class models, the most parsimonious model indicated that the survival rate of juveniles and yearlings varied significantly among sites, whereas there was less 


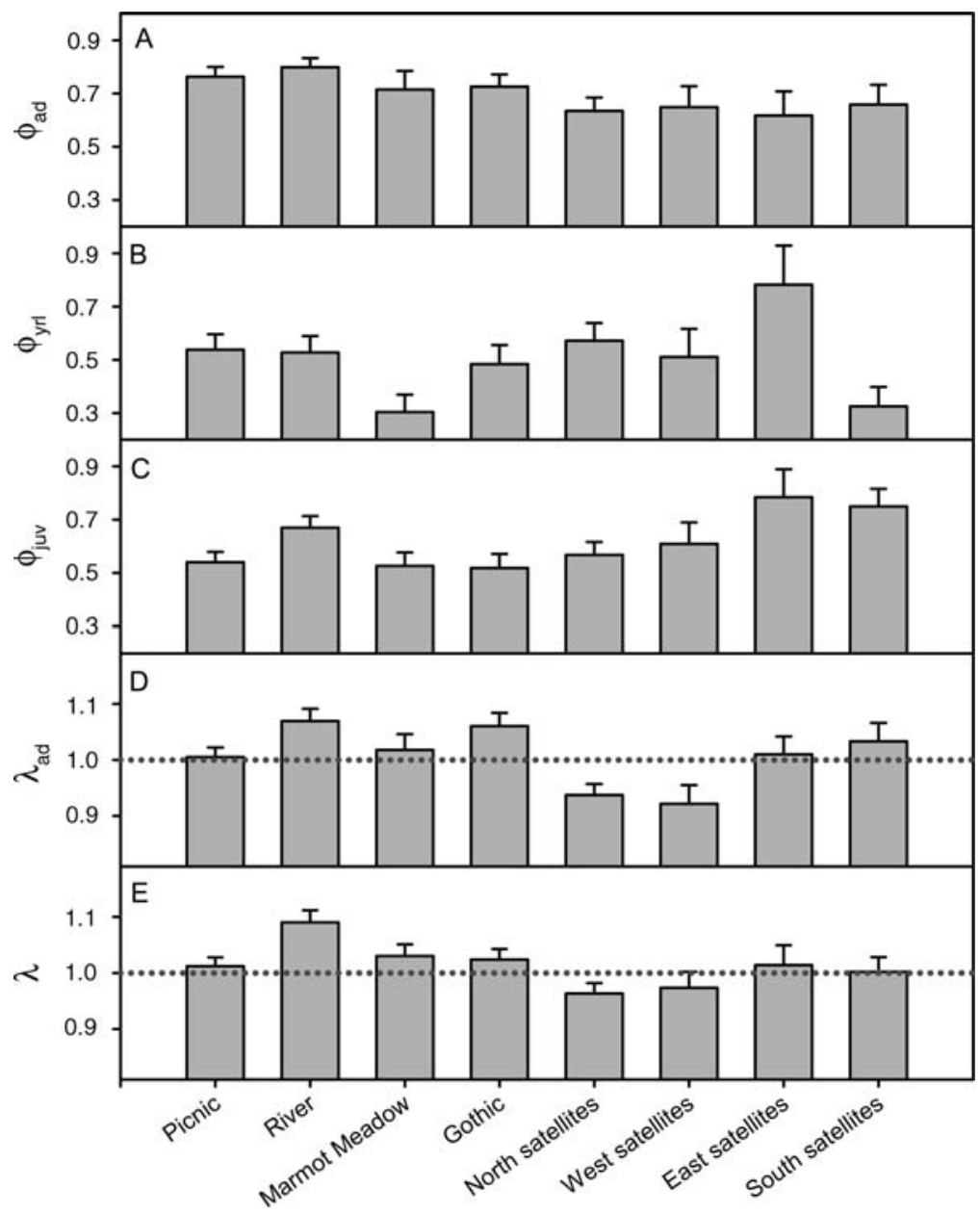

FIg. 2. (A-C) Spatial variation in annual (A) adult $\left(\phi_{\mathrm{ad}}\right)$, (B) yearling $\left(\phi_{\mathrm{yrl}}\right)$, and $(\mathrm{C})$ juvenile $\left(\phi_{\text {juv }}\right)$ survival rates. Mean values and standard errors were estimated using model 2 in Table 1. (D, E) Spatial variation in the growth rate of the (D) adult segment of the population $\left(\lambda_{\mathrm{ad}}\right)$ and $(\mathrm{E})$ entire population $(\lambda)$. Mean values and standard errors were estimated using model 6 and model 2 in Table 3, respectively.

support for site effect in adult survival rates (Table 1, model 6). However, these two models (models 2 and 6) did not differ significantly $\left(\Delta \mathrm{AIC}_{\mathrm{c}}<3\right)$, and we chose to continue our analysis with the model including site effect in all three age classes (Table 1, model 2). Juvenile survival rates were relatively low in three colony sites, Picnic (0.54; 95\% CL: $0.46,0.62$, all values are mean and 95\% CL), Marmot Meadow (0.53; 95\% CL: 0.43, 0.63), and Gothic $(0.52 ; 95 \%$ CL: $0.42,0.62)$, whereas they were the highest in east $(0.78 ; 95 \%$ CL: $0.52,0.92)$ and south satellite sites (0.75; 95\% CL: 0.60, 0.86; Fig. 2C). Yearling survival rates were the lowest in Marmot Meadow (0.30; 95\% CL: $0.19,0.45)$ and south satellites $(0.33 ; 95 \%$ CL: $0.20,0.48)$, and the highest in east satellites $(0.78 ; 95 \%$ CL: 0.40, 0.95; Fig. 2B). Adult survival rates were higher in colony sites $(0.76 ; 95 \%$ CL: $0.72,0.80)$ than in satellite sites $(0.64$; 95\% CL: 0.57, 0.71; Fig. 2A). Adult survival rates were generally higher than juvenile and yearling survival rates in colony sites; however, there was no apparent trend in satellite sites. The greatest spatial variation was observed in the survival of yearlings $(\sigma=$ $0.11)$. Spatial variation in juvenile survival $(\sigma=0.08)$ was slightly lower than in yearling survival, but higher than in adult survival rates $(\sigma=0.04)$.

Analysis of recapture rates with age structure revealed that the model with the modified site effect $\left(s^{\prime}\right)$ remained the most parsimonious recapture rate model. Thus, we used the three-age-class model with site effect for all age classes as the base survival model and the modified site effect model as the base recapture model (Table 1, model 2) for all subsequent analyses.

Next, we tested for temporal variation in the agespecific survival rates for each site. The best model structure included the additive effect of time on juvenile survival rates, and no time effect on yearling or adult survival rates (Table 2, model 3). Grouping sites into two quality types (colony and satellite sites) resulted in a more parsimonious model for the adult and juvenile survival rates. The model with separate adult survival rates for colony and satellite sites (Table 2, model 18) 
TABLE 2. Analysis of temporal variation in age-specific apparent survival rates for the yellow-bellied marmot using age structured Cormack-Jolly-Seber models.

\begin{tabular}{|c|c|c|c|c|c|}
\hline No. & Model & $\mathrm{AIC}_{\mathrm{c}}$ & $\Delta \mathrm{AIC}_{\mathrm{c}}$ & $\mathrm{w}_{i}$ & np \\
\hline 1 & $\phi_{\mathrm{juv}}(s) \phi_{\mathrm{yrl}}(s) \phi_{\mathrm{ad}}(s) \rho\left(s^{\prime}\right)$ & 2622.63 & 34.25 & 0.000 & 30 \\
\hline 2 & $\phi_{\text {juv }}(t) \phi_{\mathrm{yrl}}(s) \phi_{\mathrm{ad}}(s) \rho\left(s^{\prime}\right)$ & 2613.02 & 24.64 & 0.000 & 49 \\
\hline 3 & $\phi_{\text {juv }}(t+s) \phi_{\text {yrl }}(s) \phi_{\text {ad }}(s) \rho\left(s^{\prime}\right)$ & 2607.26 & 18.88 & 0.000 & 56 \\
\hline 4 & $\phi_{\text {juv }}(t \times s) \phi_{\text {yrl }}(s) \phi_{\text {ad }}(s) \rho\left(s^{\prime}\right)$ & 2655.41 & 67.03 & 0.000 & 179 \\
\hline 5 & $\dot{\phi}_{\mathrm{juv}}(t+s) \dot{\phi}_{\mathrm{yrl}}(t) \phi_{\mathrm{ad}}(s) \rho\left(s^{\prime}\right)$ & 2624.92 & 36.54 & 0.000 & 73 \\
\hline 6 & $\phi_{\text {juv }}(t+s) \phi_{\mathrm{yrl}}(t+s) \phi_{\mathrm{ad}}(s) \rho\left(s^{\prime}\right)$ & 2628.00 & 39.62 & 0.000 & 80 \\
\hline 7 & $\phi_{\text {juv }}(t+s) \phi_{\mathrm{yrl}}(s) \phi_{\mathrm{ad}}(t) \rho\left(s^{\prime}\right)$ & 2627.00 & 38.62 & 0.000 & 73 \\
\hline 8 & $\phi_{\text {juv }}(t+s) \phi_{\mathrm{yrl}}(s) \phi_{\mathrm{ad}}(t+s) \rho\left(s^{\prime}\right)$ & 2627.82 & 39.44 & 0.000 & 80 \\
\hline 9 & $\phi_{\text {juv_col }}(t) \phi_{\text {juv_sat }}(t) \phi_{\text {yrl }}(s) \phi_{\text {ad }}(s) \rho\left(s^{\prime}\right)$ & 2602.61 & 14.23 & 0.000 & 68 \\
\hline 10 & $\phi_{\text {juv_col }}(t) \phi_{\text {juv_sat }}(s) \phi_{\text {yrl }}(s) \phi_{\text {ad }}(s) \rho\left(s^{\prime}\right)$ & 2598.72 & 10.35 & 0.003 & 52 \\
\hline 11 & $\phi_{\text {juv_col }}(s) \phi_{\text {juv_sat }}(t) \phi_{\text {yrl }}(s) \phi_{\text {ad }}(s) \rho\left(s^{\prime}\right)$ & 2625.62 & 37.24 & 0.000 & 46 \\
\hline 12 & $\phi_{\text {juv_col }}(t) \phi_{\text {juv_sat }}(\cdot) \phi_{\text {yrl }}(s) \phi_{\text {ad }}(s) \rho\left(s^{\prime}\right)$ & 2599.29 & 10.91 & 0.002 & 49 \\
\hline 13 & $\phi_{\text {juv_col }}(t+s) \phi_{\text {juv_sat }}(s) \phi_{\text {yrl }}(s) \phi_{\text {ad }}(s) \rho\left(s^{\prime}\right)$ & 2599.06 & 10.68 & 0.002 & 55 \\
\hline 14 & $\phi_{\text {juv_col }}(t) \phi_{\text {juv_sat }}(\bar{s}) \phi_{\text {yrl_col }}(s) \phi_{\text {yrl_sat }}(\cdot) \phi_{\text {ad }}(s) \rho\left(s^{\prime}\right)$ & 2602.33 & 13.95 & 0.000 & 49 \\
\hline 15 & $\phi_{\text {juv_col }}(t) \phi_{\text {juv_sat }}(s) \phi_{\text {yrl_col }}(\cdot) \phi_{\text {yrl_sat }}(s) \phi_{\text {ad }}(s) \rho\left(s^{\prime}\right)$ & 2600.15 & 11.77 & 0.001 & 49 \\
\hline 16 & $\phi_{\text {juv_col }}(t) \phi_{\text {juv_sat }}(s) \phi_{\text {yrl }}(s) \phi_{\text {ad_col }}(s) \phi_{\text {ad_sat }}(\cdot) \rho\left(s^{\prime}\right)$ & 2592.50 & 4.12 & 0.062 & 49 \\
\hline 17 & $\phi_{\text {juv_col }}(t) \phi_{\text {juv_sat }}(s) \phi_{\text {yrl }}(s) \phi_{\text {ad_col }}(\cdot) \phi_{\text {ad_sat }}(s) \rho\left(s^{\prime}\right)$ & 2594.58 & 6.20 & 0.022 & 49 \\
\hline 18 & $\phi_{\text {juv_col }}(t) \phi_{\text {juv_sat }}(s) \phi_{\text {yrl }}(s) \phi_{\text {ad_col }}(\cdot) \phi_{\text {ad_sat }}(\cdot) \rho\left(s^{\prime}\right)$ & 2588.38 & 0.00 & 0.486 & 46 \\
\hline 19 & $\phi_{\text {juv_col }}(t+s) \phi_{\text {juv_sat }}(s) \phi_{\text {yrl }}(s) \phi_{\text {ad_col }}(\cdot) \phi_{\text {ad_sat }}(\cdot) \rho\left(s^{\prime}\right)$ & 2588.67 & 0.29 & 0.421 & 49 \\
\hline
\end{tabular}

Notes: A three-age-class model was used for these analyses: juvenile (juv, 0-1 yr), yearlings (yrl. 1-2 yr), and adults (ad, $>2$ yr). Definitions are: $t$, time effect; $s$, site effect; $t \times s$, interactive effects of $t$ and $s$; and $t+s$, additive effects of $t$ and $s$. Colony (col) and satellite (sat) groups are indicated in the subscripts. Other symbols are defined in Table 1. The most parsimonious models are highlighted in bold.

was more parsimonious than the model with separate adult survival rates for each of the eight sites (Table 2 , model 10), indicating that the observed spatial variation in adult survival rates was due primarily to differences between satellite and colony sites. Juvenile survival rates varied spatially but not temporally in satellite sites, whereas they exhibited substantial temporal variation $(\sigma$ $=0.20$ ) in the colony sites (Table 2, model 18; Fig. 3C). A model with a similar support $\left(\Delta \mathrm{AIC}_{\mathrm{c}}<3\right.$; Table 2 , model 19) indicated additive effects of time and site on juvenile survival rates within the colonies. We used this final model (Table 3, model 19), which was biologically more plausible, as the base model for evaluating the effect of environmental covariates.

\section{Effect of environmental factors}

Preceding analyses revealed temporal variation in juvenile survival rates, and spatial variation in the survival rates of all three age classes. Thus, we examined the influence of temporal and site-specific covariates on juvenile survival rates and of site-specific covariates on the yearling and adult survival rates (see Appendix B for model details). Site-specific variation in juvenile survival rates was positively influenced by the aspect $(\beta=0.41$; $95 \%$ CL: $0.03,0.79$ ) and negatively influenced by elevation $(\beta=-0.24 ; 95 \%$ CL: $-0.47,-0.01)$ of each site. Site-specific variation in yearling survival rates was positively influenced by the elevation $(\beta=0.26$; 95\% CL: $0.01,0.51)$. Site-specific variation in adult survival rates was positively influenced by the average group size $(\beta=$ $0.13 ; 95 \%$ CL: $0.00,0.27)$. Temporal variation in juvenile survival rates in colonies was negatively influenced by the length of permanent snow cover $(\beta=-3.09$; $95 \%$ CL: $-5.37,-0.85)$.

\section{Influence on population growth rate}

Goodness-of-fit test indicated that the general Pradel's model for the entire population fit the data poorly $\left(\chi_{15}^{2}=\right.$ 422.7, $P<0.001)$. We, thus, used a variance inflation factor $(\hat{c}=2.79)$ in parameter estimation and model selection (White and Burnham 1999, Burnham and Anderson 2002). We used the model structure for survival and recapture rates $\left\{\phi(t+s) \rho\left(s^{\prime}\right)\right\}$ identified during the preliminary analysis, and estimated the spatial and temporal variation in the realized annual population growth rate, $\lambda$. The most parsimonious model indicated only site effect on $\lambda$ (Table 3 , model 2 ). Site-specific estimates of $\lambda$ ranged from 0.96 (95\% CL: $0.90,0.99)$ to 1.09 (95\% CL: $1.05,1.13)$; estimated realized population growth rates were $<1.0$ in two satellite sites (north and west satellites; Fig. 2E). Timespecific estimates of $\lambda$ ranged from 0.65 (95\% CI: 0.45 , $0.81)$ to 1.49 (95\% CI: 0.93 , 2.05; Fig. 3E).

The general Pradel's model for the adult segment of the population fit the data with a slight under-dispersion $\left(\chi_{56}^{2}=27.6, P=0.999\right)$. We used the model structure for adult survival and recapture rates $\left\{\phi_{\text {ad_col }}(\cdot) \phi_{\text {ad_sat }}(\cdot) \rho\right.$ $\left.\left(s^{\prime}\right)\right\}$ identified previously, and estimated the spatial and temporal variation in the annual realized adult population growth rate, $\lambda_{\mathrm{ad}}$. The most parsimonious model indicated additive effects of site and time on $\lambda_{\text {ad }}$ (Table 3 , model 8). Further grouping of sites into colony and satellites resulted in a more parsimonious model. Parameter $\lambda_{\mathrm{ad}}$ varied only spatially in satellite sites, whereas it varied only temporally in colony sites (Table 3, model 10). A model with a similar support indicated additive effects of time and site on $\lambda_{\mathrm{ad}}$ within the colonies (Table 3, model 11). Site-specific estimates of $\lambda_{\text {ad }}$ ranged from 0.92 (95\% CL: $\left.0.86,0.99\right)$ to 1.07 (95\% 


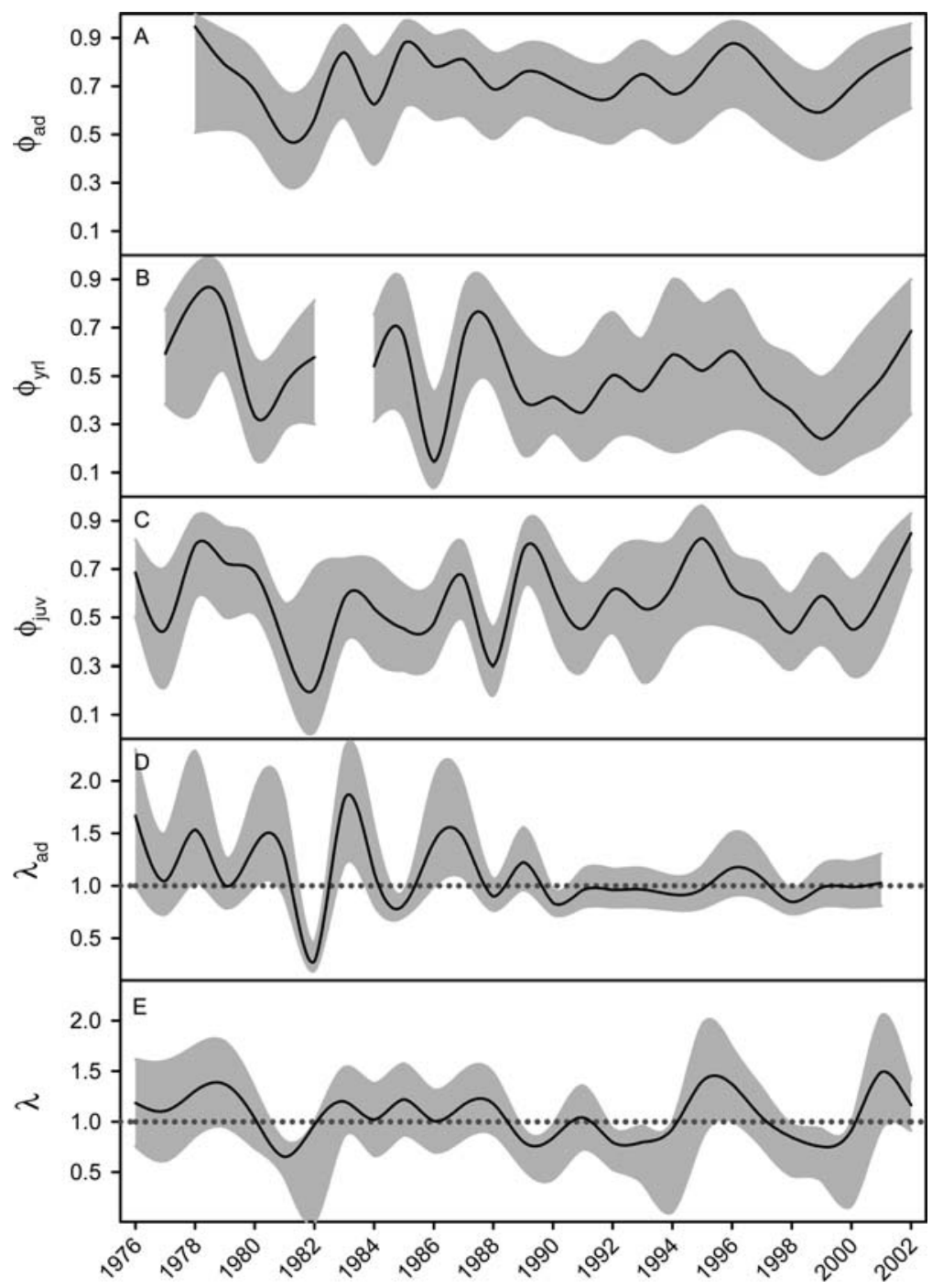

FIG. 3. (A-C) Temporal variation in annual (A) adult $\left(\phi_{\mathrm{ad}}\right)$, (B) yearling $\left(\phi_{\mathrm{yrl}}\right)$, and $(\mathrm{C})$ juvenile $\left(\phi_{\mathrm{juv}}\right)$ survival rates from 1976 to 2003. Mean values (solid line) and $95 \%$ confidence intervals (gray shade) were estimated using model 7, model 5, and model 18 in Table 2, respectively, for the different age classes. The gap in (B) indicates that the parameter was not estimable. (D, E) Temporal variation in the growth rate of the (D) adult segment of the population $\left(\lambda_{\mathrm{ad}}\right)$ with one year lag, and (E) entire population $(\lambda)$. Mean values (solid line) and 95\% confidence intervals (gray shade) were estimated using model 10 and model 3 in Table 3, respectively, for panels (D) and (E).

CL: $1.03,1.11) ; \lambda_{\text {ad }}$ was $<1.0$ only in north and west satellite sites (Fig. 2D). Annual estimates of $\lambda_{\mathrm{ad}}$ in colony sites ranged from 0.28 (95\% CL: $0.19,0.47)$ to 1.83 (95\% CL: $1.20,2.30) ; \lambda_{\text {ad }}$ exhibited substantial temporal fluctuations (Fig. 3D).

Because of the poor fit of the general Pradel's model (i.e., model for overall population growth rate, $\lambda$ ) to data, we conducted additional analyses focusing on the adult segment of the population. The $\lambda_{\text {ad }}$ covaried most closely with juvenile survival rates over space (Fig. 2) as well as over time with a one-year lag (Fig. 3). Spatial variation in $\lambda_{\mathrm{ad}}$ was significantly influenced by amongsite variation in juvenile survival rates $(\beta=0.36$; 95\% CL: $0.14,0.58$; Table 3 , model 12 ), but not by that in yearling $(\beta=-0.03$, 95\% CL: $-0.19,0.12$; Table 3 , model 13) or adult ( $\beta=0.17 ; 95 \%$ cL: $-0.43,0.77$; Table 3 , model 14$)$ survival rates. Temporal variation in $\lambda_{\mathrm{ad}}$ was significantly influenced by temporal variation in juvenile survival rates of the preceding year $(\beta=0.76,95 \%$ CL: $0.39,1.12$; Table 3 , model 15 ) and yearling survival rates ( $\beta=0.40,95 \%$ CL: $0.02,0.79$; Table 3 , model 16$)$, but not by that in adult survival rates $(\beta=-0.44,95 \% \mathrm{CL}:-1.08$, 0.19; Table 3, model 17).

\section{DisCUSSION}

Spatiotemporal variation in vital demographic rates is a common phenomenon in animal populations, and such variation can have important population dynamic consequences. However, rigorous investigations into population dynamic consequences of spatiotemporal 
TABLE 3. Analysis of the temporal and spatial variation in growth rate of the entire population $(\lambda)$ and adult (animals $>2$ yr old) segment of the population ( $\left.\lambda_{\mathrm{ad}}\right)$, using Pradel's reverse-time models.

\begin{tabular}{|c|c|c|c|c|c|}
\hline No. & Model & $\mathrm{AIC}_{\mathrm{c}}$ & $\Delta \mathrm{AIC}_{\mathrm{c}}$ & $\mathrm{w}_{i}$ & np \\
\hline \multicolumn{6}{|c|}{ Entire population: } \\
\hline 1 & $\phi(t+s) \rho\left(s^{\prime}\right) \lambda(\cdot)$ & 2994.63 & 13.92 & 0.001 & 41 \\
\hline 2 & $\phi(t+s) \rho\left(s^{\prime}\right) \lambda(s)$ & 2982.24 & 1.53 & 0.318 & 48 \\
\hline 3 & $\phi(t+s) \rho\left(s^{\prime}\right) \lambda(t)$ & 2994.64 & 13.93 & 0.001 & 67 \\
\hline 4 & $\phi(t+s) \rho\left(s^{\prime}\right) \lambda(t+s)$ & 2980.71 & $\mathbf{0 . 0 0}$ & 0.681 & 74 \\
\hline \multicolumn{6}{|c|}{ Adult segment of the population: } \\
\hline 5 & $\phi_{\text {ad_col }}(\cdot) \phi_{\text {ad_sat }}(\cdot) \rho\left(s^{\prime}\right) \lambda_{\text {ad }}(\cdot)$ & 2183.36 & 67.29 & 0.000 & 9 \\
\hline 6 & $\phi_{\text {ad_col }}(\cdot) \phi_{\text {ad_sat }}(\cdot) \rho\left(s^{\prime}\right) \lambda_{\text {ad }}(s)$ & 2162.98 & 46.91 & 0.000 & 16 \\
\hline 7 & $\phi_{\text {ad_col }}(\cdot) \phi_{\text {ad_sat }}(\cdot) \rho\left(s^{\prime}\right) \lambda_{\text {ad }}(t)$ & 2158.97 & 42.90 & 0.000 & 35 \\
\hline 8 & $\phi_{\text {ad_col }}(\cdot) \phi_{\text {ad_sat }}(\cdot) \rho\left(s^{\prime}\right) \lambda_{\text {ad }}(t+s)$ & 2127.72 & 11.65 & 0.003 & 42 \\
\hline 9 & $\phi_{\text {ad_col }}(\cdot) \phi_{\text {ad_sat }}(\cdot) \rho\left(s^{\prime}\right) \lambda_{\text {ad_col }}(t) \lambda_{\text {ad_sat }}(t)$ & 2140.51 & 24.44 & 0.000 & 36 \\
\hline 10 & $\phi_{\text {ad_col }}(\cdot) \phi_{\text {ad_sat }}(\cdot) \rho\left(s^{\prime}\right) \lambda_{\text {ad_col }}(t) \lambda_{\text {ad_sat }}(s)$ & 2120.58 & 4.51 & 0.090 & 37 \\
\hline 11 & $\phi_{\text {ad_col }}(\cdot) \phi_{\text {ad_sat }}(\cdot) \rho\left(s^{\prime}\right) \lambda_{\text {ad_col }}(t+s) \lambda_{\text {ad_sat }}(s)$ & 2122.19 & 6.12 & 0.040 & 42 \\
\hline 12 & $\phi_{\text {ad_col }}(\cdot) \phi_{\text {ad_sat }}(\cdot) \rho\left(s^{\prime}\right) \lambda_{\text {ad_col }}\left(t+j u v_{s}\right) \lambda_{\text {ad_sat }}\left(j u v_{s}\right)$ & 2116.07 & 0.00 & 0.857 & 35 \\
\hline 13 & $\phi_{\text {ad_col }}(\cdot) \phi_{\text {ad_sat }}(\cdot) \rho\left(s^{\prime}\right) \lambda_{\text {ad_col }}\left(t+y r l_{s}\right) \lambda_{\text {ad_sat }}\left(y r l_{s}\right)$ & 2126.46 & 10.39 & 0.005 & 35 \\
\hline 14 & $\phi_{\text {ad_col }}(\cdot) \phi_{\text {ad_sat }}(\cdot) \rho\left(s^{\prime}\right) \lambda_{\text {ad_col }}\left(t+a d_{s}\right) \lambda_{\text {ad_sat }}\left(a d_{s}\right)$ & 2126.33 & 10.25 & 0.005 & 35 \\
\hline 15 & $\phi_{\text {ad_col }}(\cdot) \phi_{\text {ad_sat }}(\cdot) \rho\left(s^{\prime}\right) \lambda_{\text {ad_col }}\left(j u v_{t-1}+s\right) \lambda_{\text {ad_sat }}(s)$ & 2151.99 & 35.91 & 0.000 & 17 \\
\hline 16 & $\phi_{\text {ad_col }}(\cdot) \phi_{\text {ad_sat }}(\cdot) \rho\left(s^{\prime}\right) \lambda_{\text {ad_col }}\left(y r l_{t}+s\right) \lambda_{\text {ad_sat }}(s)$ & 2161.01 & 44.94 & 0.000 & 17 \\
\hline 17 & $\phi_{\text {ad_col }}(\cdot) \phi_{\text {ad_sat }}(\cdot) \rho\left(s^{\prime}\right) \lambda_{\text {ad_col }}\left(a d_{t}+s\right) \lambda_{\text {ad_sat }}(s)$ & 2163.21 & 47.14 & 0.000 & 17 \\
\hline
\end{tabular}

Notes: Site-specific covariates for $\lambda_{\text {ad }}$ are juvenile $\left(\mathrm{juv}_{s}\right)$, yearling $\left(\mathrm{yrl}_{s}\right)$, and adult $\left(\mathrm{ad}_{s}\right)$ survival rates, and temporal covariates for $\lambda_{\mathrm{ad}}$ are juvenile survival rate of the previous year $\left(\mathrm{juv}_{t-1}\right)$, and yearling $\left(\mathrm{yrl}_{t}\right)$ and adult $\left(\mathrm{ad}_{t}\right)$ survival rates of the current year. Other symbols are defined in Tables 1 and 2. The most parsimonious models are highlighted in bold.

variation in age-specific vital rates require data at large spatial and temporal scales. Consequently, there have been relatively few studies that explicitly considered both sources of variation. Our long-term study of individually identified animals in several discrete habitat patches provided adequate data for a rigorous examination of spatiotemporal patterns in age-specific survival rates of yellow-bellied marmots and their population dynamic consequences.

In general, overall survival rates of yellow-bellied marmots varied both spatially and temporally. Detailed analysis of age-specific survival rates indicated that the pattern of variation differed among age classes. The most appropriate age structure was the three-age-class model: juveniles $(0-1 \mathrm{yr})$, yearlings ( $1-2 \mathrm{yr})$, and adults $(>2)$, suggesting that the survival rates significantly differed among these three age classes. Previous studies on other ground squirrels reported higher survival rates for adults, and lower rates for young animals (Bronson 1979, Farand et al. 2002). Survival rates of adult yellowbellied marmots in Colorado were generally higher than those of the younger age classes; however, this trend was consistent only in high quality colony sites. There was no significant difference between the adult and juvenile survival rates in the lower quality satellite sites. Hence, our results indicate that differences in habitat quality can differentially affect age-specific survival rates in sciurid rodent populations. Yearling survival rates were, in general, lower than adult and juvenile survival rates. We note, however, that the estimated survival rates were apparent, rather than true, survival rates. Yearling marmots are much more likely to disperse than juveniles or adults (Van Vuren 1990, Van Vuren and Armitage 1994). As a result, estimates of yearling survival rates were confounded by permanent emigration out of the study area, and therefore, are likely to be underestimated.

Spatial variation in survival rates was observed in all three age classes; however, the degree of spatial variation differed among age classes. The spatial variation in the survival rate of younger animals was greater than that of adults, and it was influenced by the aspect and the elevation of each site. Juvenile survival rates on southwest facing slopes were higher than those on northeast facing slopes. Aspect of each site determines the amount of exposure to sunlight and duration of snow cover, which in turn, determines the length of the active season and hibernation period at a given site. These factors have been suggested as important determinants of juvenile survival (Van Vuren and Armitage 1991). Bronson (1979) reported no effect of elevation on the survival of juvenile golden-mantled ground squirrels (Spermophilus lateralis), whereas survival of juvenile marmots was negatively associated with elevation in our study population. Survival of the juveniles did not differ significantly between satellite and colony sites (see also Lenihan and Van Vuren 1996); they were actually higher in two satellite sites (Fig. 2C). Juvenile survival rates are likely to be affected by differences in microclimate owing mostly to the differences in aspect and elevation among sites (Armitage 1994).

Adult survival rates differed only between the colony and satellite sites, with generally higher survival rates in colony sites. Colony sites, characterized by large habitat area and more abundant resources (e.g., adequate hibernation opportunity, protection from predation, higher food availability) are usually inhabited by large groups, whereas satellite sites, characterized by smaller 
habitat area and limited resources, sustain fewer adults (Armitage 1991, 1998). The risk of predation during the active season, and/or mortality during hibernation, are likely to be higher in satellite sites, resulting in lower adult survival. Our results were consistent with those of Armitage and Schwartz (2000) that average group size was positively associated with survival rate of adult animals. Zammuto and Millar (1985) and Bronson (1979) indicated that adult survival rates were higher at higher elevations for some ground squirrel populations. Gillis et al. (2005), on the other hand, reported that annual survival rates of the adult arctic ground squirrels (Spermophilus parryii pleisus) did not vary with elevation, but noted a trade-off between active season and overwinter survival. We did not observe a positive association between elevation and survival of adult marmots. It is important to note that the range of elevational gradient in our study sites was smaller than that in aforementioned studies.

The additive effect of time in the overall survival rates primarily reflected temporal variation in juvenile survival rates; there was no support for the temporal variation in yearling or adult survival rates. A model of synchronous temporal variation in survival rates among colony sites (i.e., the additive effects of time and space) was supported by the data more strongly than was an asynchronous temporal variation model (i.e., the interactive effects of time and space), suggesting that regional climatic factors were likely to be the main cause of such variation (Schwartz and Armitage 2005). Multiple environmental and social factors may act synergistically to influence survival rates of marmots in our metapopulation, and the individual or combined effect of a few factors cannot account for the observed variation. Nonetheless, our results suggest that juvenile survival rates were mainly influenced by environmental factors that determined the duration of snow cover, whereas survival of older animals was mostly influenced by social factors such as group size. The precise mechanisms underlying these effects require further study. Differential predation on adults as a function of site is strongly implicated by previous studies (Van Vuren 2001; Blumstein et al., in press), and prior work also suggests that predation may vary temporally (Armitage 2004).

The variation in age-specific survival rates over space and time were naturally reflected in spatial and temporal variation in population growth rates. Growth rate of the entire population $(\lambda)$ and of the adult segment of the population $\left(\lambda_{\mathrm{ad}}\right)$ followed a pattern that primarily reflected site-specific differences in juvenile survival rates. Modeling $\lambda_{\text {ad }}$ as a function of age-specific survival rates revealed that spatial variation in $\lambda_{\mathrm{ad}}$ was significantly influenced by survival of juveniles but not of yearlings or adults. Likewise, $\lambda_{\text {ad }}$ closely covaried over time with survival of juveniles with a one-year time lag. Because survival of yearlings and adults did not vary significantly over time, it seems reasonable to conclude that most of the observed temporal variation in population growth rate was due primarily to temporal variation in survival of juveniles. These results suggest that spatial and temporal variation in population dynamics of yellow-bellied marmots was strongly influenced by spatiotemporal variation in juvenile survival rates.

It has been suggested that vital demographic rates with the greatest potential influence on population growth rate tend to exhibit the least temporal (or spatial) variability (Cairns 1992, Gaillard et al. 1998, Pfister 1998, Gaillard et al. 2000). In yellow-bellied marmots, the asymptotic population growth rate is highly sensitive to variation in juvenile survival rates (Oli and Armitage 2004). However, we found that, among all age-specific survival rates, survival of juveniles was the most variable over space and time. This variation heavily influenced the dynamics of our study population; site-specific and temporal variation in population growth rate closely covaried with, and primarily reflected spatiotemporal variation in survival of juveniles. Thus, the high variability in juvenile survival rates over space and time clearly influenced the dynamics of our study population, and is also likely to be an important determinant of the spatiotemporal variation in the population dynamics of other mammals with similar life history characteristics. Higher spatiotemporal variability in the survival of younger age classes has been reported for other long-lived vertebrate species (e.g., Douglas and Leslie 1986, Clutton-Brock et al. 1987, Gaillard et al. 1998, Portier et al. 1998); however, its effects on population dynamics were rarely addressed.

We conclude that survival rates of yellow-bellied marmots exhibit both spatial and temporal variation, but that survival of juveniles is more variable over space and time than that of older animals. Spatial and temporal variation in juvenile survival rates strongly influenced the temporal variation in the growth rates of our study population. Given the high variability in survival rates of younger age classes, and the high sensitivity of population dynamics to these rates in several species of mammals (Oli and Dobson 2003), future modeling attempts should thoroughly incorporate the spatiotemporal variation in the survival of younger age classes, and carefully examine population dynamic consequences of such variations. We note, however, that adult survival may have a greater influence than juvenile survival on the population dynamics of some long-lived vertebrates (e.g., Doak et al. 1994, Caswell et al. 1999, Gaillard et al. 2000), suggesting that the generality of our conclusions may be limited to species with life histories similar to the yellow-bellied marmot.

\section{ACKNOWLEDGMENTS}

We thank all the "marmoteers" who participated in the fieldwork; this work would not have been possible without their dedicated help. A. Bronikowski, G. Cumming, R. Holt, K. Sieving, and an anonymous reviewer provided many insightful comments. Our research was partially supported by Lee R.G. 
Snyder Memorial Fund (A. Ozgul), Sigma Xi Grant-in-Aid of Research (A. Ozgul), Florida Agricultural Experiment Station, National Science Foundation grants DEB-0224953 (M. K. Oli), G16354, GB-1980, GB-6123, GB-32494, BMS74-21193, DEB78-07327, BSR-8121231, BSR8614690, BSR-9006772 (K. B. Armitage), DBI-0242960 (to Rocky Mountain Biological Laboratory), a UCLA Career Development Award, and Faculty Research Grants (D. T. Blumstein).

\section{Literature Cited}

Armitage, K. B. 1991. Social and population dynamics of yellow-bellied marmots: results from long-term research. Annual Review of Ecology and Systematics 22:379-407.

Armitage, K. B. 1994. Unusual mortality in a yellow-bellied marmot population. Pages 5-13 in V. Y. Rumiantsev, editor. Actual problems of marmot investigation. ABF Publishing House, Moscow, Russia.

Armitage, K. B. 1998. Reproductive strategies of yellow-bellied marmots: energy conservation and differences between the sexes. Journal of Mammalogy 79:385-393.

Armitage, K. B. 2003. Marmots: (Marmota monax and allies). Pages 188-210 in G. A. Feldhamer, B. C. Thompson, and J. A. Chapman, editors. Wild mammals of North America: biology, management, and conservation. Second edition. Johns Hopkins University Press, Baltimore, Maryland, USA.

Armitage, K. B. 2004. Badger predation on yellow-bellied marmots. American Midland Naturalist 151:378-387.

Armitage, K. B., and O. A. Schwartz. 2000. Social enhancement of fitness in yellow-bellied marmots. Proceedings of the National Academy of Sciences (USA) 97:12149-12152.

Blums, P., J. D. Nichols, J. E. Hines, and A. Mednis. 2002. Sources of variation in survival and breeding site fidelity in three species of European ducks. Journal of Animal Ecology 71:438-450.

Blumstein, D. T., A. Ozgul, V. Yovovich, D. H. Van Vuren, and $\mathrm{K}$. B. Armitage. In press. Effect of predation risk on presence and persistence of yellow-bellied marmot colonies. Journal of Zoology, London.

Bronson, M. T. 1979. Altitudinal variation in the life-history of the golden-mantled ground-squirrel (Spermophilus lateralis). Ecology 60:272-279.

Burnham, K. P., and D. R. Anderson. 2002. Model selection and inference: a practical information-theoretic approach. Second edition. Springer-Verlag, New York, New York, USA.

Burnham, K. P., D. R. Anderson, G. C. White, C. Brownie, and K. H. Pollock. 1987. Design and analysis methods for fish survival experiments based on release-capture. American Fisheries Society Monograph 5:1-437.

Cairns, D. K. 1992. Population regulation of seabird colonies. Current Ornithology 9:37-61.

Caswell, H., M. Fujiwara, and S. Brault. 1999. Declining survival probability threatens the North Atlantic right whale. Proceedings of the National Academy of Sciences (USA) 96: 3308-3313.

Choquet, R., A. M. Reboulet, R. Pradel, O. Gimenez, and J. D. Lebreton. 2003. User's manual for U-Care. Mimeographed document, CEFE/CNRS, Montpellier, France. 〈http://www. cefe.cnrs.fr/biom/ $/$

Clutton-Brock, T. H., M. Major, S. D. Albon, and F. E. Guinness. 1987. Early development and population dynamics in red deer. 1. Density-dependent effects on juvenile survival. Journal of Animal Ecology 56:53-67.

Coulson, T., S. Albon, J. Pilkington, and T. Clutton-Brock. 1999. Small-scale spatial dynamics in a fluctuating ungulate population. Journal of Animal Ecology 68:658-671.

Coulson, T., E. J. Milner-Gulland, and T. Clutton-Brock. 2000. The relative roles of density and climatic variation on population dynamics and fecundity rates in three contrasting ungulate species. Proceedings of the Royal Society of London Series B 267:1771-1779.
Doak, D., P. Kareiva, and B. Kleptetka. 1994. Modeling population viability for the desert tortoise in the western Mojave Desert. Ecological Applications 4:446-460.

Dobson, F. S., and M. K. Oli. 2001. The demographic basis of population regulation in Columbian ground squirrels. American Naturalist 158:236-247.

Doherty, P. F., E. A. Schreiber, J. D. Nichols, J. E. Hines, W. A. Link, G. A. Schenk, and R. W. Schreiber. 2004. Testing life history predictions in a long-lived seabird: a population matrix approach with improved parameter estimation. Oikos 105:606-618.

Douglas, C. L., and D. M. Leslie. 1986. Influence of weather and density on lamb survival of desert mountain sheep. Journal of Wildlife Management 50:153-156.

Farand, E., D. Allaine, and J. Coulon. 2002. Variation in survival rates for the alpine marmot (Marmota marmota): effects of sex, age, year, and climatic factors. Canadian Journal of Zoology 80:342-349.

Fowler, C. W., and T. D. Smith. 1981. Dynamics of large mammal populations. Wiley, New York, New York, USA.

Francis, C. M. 1995. Estimating survival rates from recoveries of birds ringed as young: a case study. Journal of Applied Statistics 22:567-577.

Franklin, A. B. 2001. Exploring ecological relationships in survival and estimating rates of population change using program MARK. Pages 290-296 in R. Field, R. J. Warren, H. Okarma, and P. R. Sievert, editors. Wildlife, land, and people: priorities for the 21st century. Second International Wildlife Management Congress. The Wildlife Society, Bethesda, Maryland, USA.

Frase, B. A., and R. S. Hoffmann. 1980. Marmota flaviventris. Mammalian Species 135:1-8.

Gaillard, J. M., M. Festa-Bianchet, and N. G. Yoccoz. 1998. Population dynamics of large herbivores: variable recruitment with constant adult survival. Trends in Ecology and Evolution 13:58-63.

Gaillard, J. M., M. Festa-Bianchet, N. G. Yoccoz, A. Loison, and C. Toigo. 2000. Temporal variation in fitness components and population dynamics of large herbivores. Annual Review of Ecology and Systematics 31:367-393.

Gillis, E. A., D. S. Hik, R. Boonstra, T. J. Karels, and C. J. Krebs. 2005. Being high is better: effects of elevation and habitat on arctic ground squirrel demography. Oikos 108: 231-240.

Graham, I. M., and X. Lambin. 2002. The impact of weasel predation on cyclic field-vole survival: the specialist predator hypothesis contradicted. Journal of Animal Ecology 71:946956.

Heppell, S. S., H. Caswell, and L. B. Crowder. 2000. Life histories and elasticity patterns: perturbation analysis for species with minimal demographic data. Ecology 81:654-665.

Jorgenson, J. T., M. Festa-Bianchet, J. M. Gaillard, and W. D. Wishart. 1997. Effects of age, sex, disease, and density on survival of bighorn sheep. Ecology 78:1019-1032.

Kareiva, P. 1990. Population-dynamics in spatially complex environments: theory and data. Philosophical Transactions of the Royal Society of London Series B 330:175-190.

Lebreton, J. D., K. P. Burnham, J. Clobert, and D. R. Anderson. 1992. Modeling survival and testing biological hypotheses using marked animals: a unified approach with case studies. Ecological Monographs 62:67-118.

Lebreton, J. D., R. Pradel, and J. Clobert. 1993. The statistical analysis of survival in animal populations. Trends in Ecology and Evolution 8:91-95.

Lenihan, C., and D. VanVuren. 1996. Costs and benefits of sociality in yellow-bellied marmots (Marmota flaviventris): Do noncolonial females have lower fitness? Ethology, Ecology and Evolution 8:177-189.

Nichols, J. D., and J. E. Hines. 2002. Approaches for the direct estimation of $\lambda$, and demographic contributions to $\lambda$, using 
capture-recapture data. Journal of Applied Statistics 29:539568.

Nichols, J. D., T. S. Sillett, J. E. Hines, and R. T. Holmes. 2003. Approaches for the direct estimation of rate of increase in population size $(\lambda)$ using capture-recapture data. USDA Forest Service General Technical Report PSW-GTR-191.

Oli, M. K., and K. B. Armitage. 2004. Yellow-bellied marmot population dynamics: demographic mechanisms of growth and decline. Ecology 85:2446-2455.

Oli, M. K., and F. S. Dobson. 2003. The relative importance of life-history variables to population growth rate in mammals: Cole's prediction revisited. American Naturalist 161:422-440.

Orzack, S. H., and S. Tuljapurkar. 1989. Population dynamics in variable environments: 7 . The demography and evolution of iteroparity. American Naturalist 133:901-923.

Pfister, C. A. 1998. Patterns of variance in stage-structured populations: evolutionary predictions and ecological implications. Proceedings of the National Academy of Sciences (USA) 95:213-218.

Portier, C., M. Festa-Bianchet, J. M. Gaillard, J. T. Jorgenson, and N. G. Yoccoz. 1998. Effects of density and weather on survival of bighorn sheep lambs (Ovis canadensis). Journal of Zoology 245:271-278.

Post, E., N. C. Stenseth, R. Langvatn, and J. M. Fromentin. 1997. Global climate change and phenotypic variation among red deer cohorts. Proceedings of the Royal Society of London Series B 264:1317-1324.

Pradel, R. 1996. Utilization of capture-mark-recapture for the study of recruitment and population growth rate. Biometrics 52:703-709.

Pulliam, H. R., and B. J. Danielson. 1991. Sources, sinks, and habitat selection: a landscape perspective on population dynamics. American Naturalist 137:S50-S66.

Ringsby, T. H., B. E. Sæther, R. Altwegg, and E. J. Solberg. 1999. Temporal and spatial variation in survival rates of a house sparrow, Passer domesticus, metapopulation. Oikos 85: 419-425.

Sæther, B. E. 1997. Environmental stochasticity and population dynamics of large herbivores: A search for mechanisms. Trends in Ecology and Evolution 12:143-149.

Sæther, B. E., and O. Bakke. 2000. Avian life history variation and contribution of demographic traits to the population growth rate. Ecology 81:642-653.

Sæther, B. E., T. H. Ringsby, O. Bakke, and E. J. Solberg. 1999. Spatial and temporal variation in demography of a house sparrow metapopulation. Journal of Animal Ecology 68:628637.

Schwartz, O. A., and K. B. Armitage. 2005. Weather influences on demography of the yellow-bellied marmot (Marmota flaviventris). Journal of Zoology 265:73-79.

Schwartz, O. A., K. B. Armitage, and D. Van Vuren. 1998. A 32-year demography of yellow-bellied marmots (Marmota flaviventris). Journal of Zoology 246:337-346.

Stearns, S. 1992. Evolution of life histories. Oxford University Press, Oxford, UK.

Svendsen, G. E. 1974. Behavioral and environmental factors in spatial distribution and population dynamics of a yellowbellied marmot population. Ecology 55:760-771.

Tilman, D., and P. Kareiva. 1997. Spatial Ecology. Princeton University Press, Princeton, New Jersey, USA.

Tuljapurkar, S. D. 1990. Population dynamics in variable environments. Springer-Verlag, New York, New York, USA.

Van Vuren, D. 1990. Dispersal of yellow-bellied marmots. Dissertation. University of Kansas, Lawrence, Kansas, USA.

Van Vuren, D. H. 2001. Predation on yellow-bellied marmots (Marmota flaviventris). American Midland Naturalist 145: 94-100.

Van Vuren, D. H., and K. B. Armitage. 1991. Duration of snow cover and its influence on life-history variation in yellowbellied marmots. Canadian Journal of Zoology 69:17551758.

Van Vuren, D., and K. B. Armitage. 1994. Survival of dispersing and philopatric yellow-bellied marmots: what is the cost of dispersal? Oikos 69:179-181.

Waser, P. M., L. F. Elliott, N. M. Creel, and S. R. Creel. 1995. Habitat variation and mongoose demography. Pages $421-$ 450 in A. R. E. Sinclear and P. Arcese, editors. Serengeti II: dynamics, management and conservation of an ecosystem. University of Chicago Press, Chicago, Illinois, USA.

White, G. C., and K. P. Burnham. 1999. Program MARK: survival estimation from populations of marked animals. Bird Study 46:120-139.

Williams, B. K., J. D. Nichols, and M. J. Conroy. 2001. Analysis and management of animal populations. Academic Press, San Diego, California, USA.

Zammuto, R. M., and J. S. Millar. 1985. Environmental predictability, variability, and Spermophilus columbianus life history over an elevational gradient. Ecology 66:1784-1794.

\section{APPENDIX A}

Analysis of spatial and temporal variation in overall apparent annual survival rates for yellow-bellied marmots using CormackJolly-Seber models (Ecological Archives E087-059-A1).

\section{APPENDIX B}

A table showing the effect of environmental covariates on the spatial and temporal variation in age-specific survival rates (Ecological Archives E087-059-A2). 